\title{
Perineal groove leading to a suspicion of child sexual abuse
}

\section{S M H M K Senanayake', U A K Tennakoon ${ }^{2}$}

Ceylon Medical Journal 2014; 59: 147-148

The child's guardian, the grandmother discovered a red ulcer in the perineum of a two years and two months old baby girl during bathing. She did not remember excessive crying or blood in the baby's clothes in the recent past but could not confidently exclude child abuse because drunken friends of her husband used to visit their house. Medical officers suspected anal penetration with a tear extending to the vulva.

Examination showed a well nourished baby without any bodily injury or old traumatic scars. Genital examination revealed a triangular shaped gradual narrowing of the posterior fourchette continuing as a 2 $\mathrm{mm}$ wide, $5 \mathrm{~mm}$ deep midline red groove into the anus and up to the anterior wall of the anus. There was no contact bleeding or granulation tissue to suggest the groove was a result of injury. Base of the anterior wider triangular part of the groove was covered with the continuation of vulval mucous membrane (Figure 1 and 2). The hymen was of annular type and was intact. The hymenal orifice was about $2 \mathrm{~mm}$ in diameter. Anal sphincter was normal. This was a rare developmental defect known as perineal groove, a wet sulcus that extends from the posterior fourchette to the anus [1]. When it presents late, medical practitioners tend to misdiagnose it for dermatological conditions $[2,3]$.

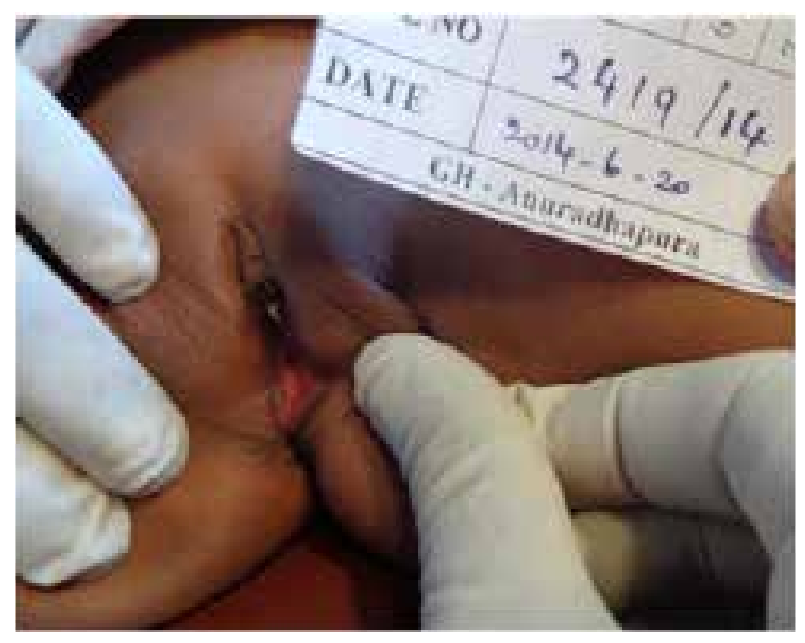

Figure 1.

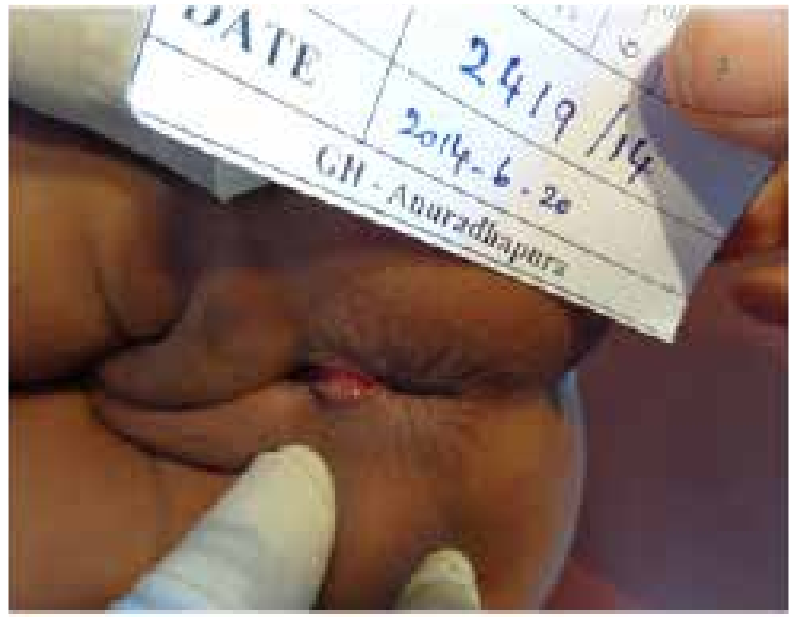

Figure 2.

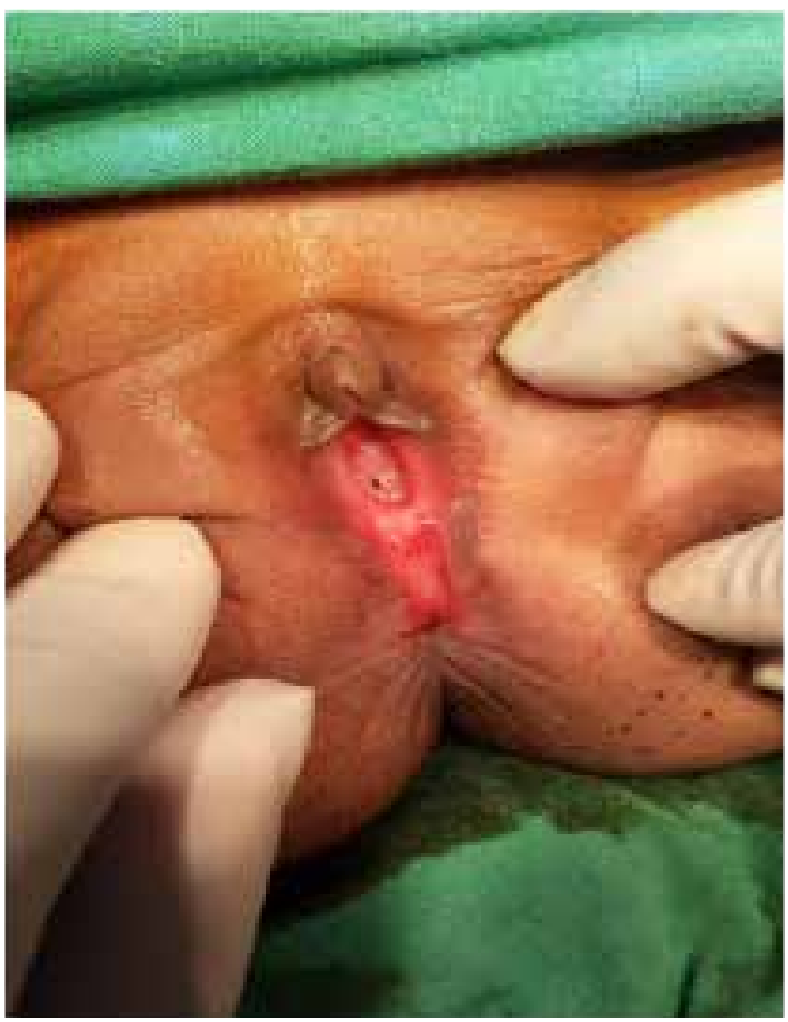

Figure 3.

Judicial Medical Officer, ${ }^{1}$ Teaching Hospital, Anuradhapura and ${ }^{2}$ Colombo, Sri Lanka.

Correspondence: SMHMKS, e-mail: <senanayakekumara@yahoo.com>. Received 2 July 2014 and revised version accepted 6 October 2014. Competing interests: none declared. 
This congenital deformity was differentiated from an injury because of regular margins, absence of evidence of healing (granulation tissue or scarring edges), absence of other associated injuries or scars, and the distribution of the lesion exactly in the midline with equal depth throughout the course. Traumatic tears (lacerations) become shallow gradually before disappearance have irregular edges and show evidence of healing consisting of granulation tissues in a few days, scars in the edges in weeks and ultimately a complete scar. The diagnosis in this child was established because of the mucous membrane covering the lesion which was discovered when the baby was examined under anaes-thesia [4]. Seven days after admission the lesion did not show any features of healing (Figure 3). The Police inquired why the congenital deformity was not discovered soon after birth. This was because the lesion was only visible when the buttocks were separated.

\section{References}

1. Diaz L, Levy mc, Kalajian A, Metiy D. Perineal groove: a report of 2 cases. Journal of the American Medical Association Dermatology 2014; 150: 101-2.

2. Verma SB, Wollina U. Perineal groove - a case report. Pediatric Dermatology 2010; 27: 626-7.

3. Mullassery D, Turnock R, Kokai G. Perineal groove. Journal of Paediatric Surgery 2006; 41e:41-3.

4. Sekaran P, Shawis R. Perineal groove: A rare congenital abnormality of failure of fusion of the perineal raphe and discussion of its embryological origin. Clinical Anatomy 2009; 22: 823-5. 